\title{
Evaluation of the limit of performance of an analytical method based on a statistical calculation of its critical concentrations according to iso standard 11843: Application to routine control of banned veterinary drug residues in food according to European Decision 657/2002/EC
}

\author{
E. Verdon · D. Hurtaud-Pessel · P. Sanders
}

Received: 10 October 2006 / Accepted: 18 October 2006 / Published online: 29 November 2006

(C) Springer-Verlag 2006

\section{Accred Qual Assur (2006) 11(1-2):58-62}

The hereabove mentionned article published in the April 2006 Issue No 1-2 Page 58-62 of the Journal contains a parenthesis mistake in 2 formulas of its page 59. This mistake may lead to corruption in the calculations for the readers not familiar with ISO Standard 11843-2. In the part entitled Concept of calculation of critical concentrations according to Standard ISO11843, for the calculation of $\mathrm{CC} \alpha$ and $\mathrm{CC} \beta$ applied to what is called MRL substances, it is recommended to use the following formulas where is added a set of parenthesis at the numerator of the 3rd term under the square root :

$$
\begin{aligned}
& C C \alpha=x_{M R L}+t_{(\alpha, I J-2)} \cdot \frac{\hat{\sigma}}{\hat{b}} \cdot \sqrt{\frac{1}{K}+\frac{1}{I . J}+\frac{\left(x_{M R L}-\bar{x}\right)^{2}}{\sum\left(x_{i j}-\bar{x}\right)^{2}}} \\
& C C \beta=x_{M R L}+\delta_{(I . J-2 ; \alpha ; \beta)} \cdot \frac{\hat{\sigma}}{\hat{b}} \cdot \sqrt{\frac{1}{K}+\frac{1}{I . J}+\frac{\left(x_{M R L}-\bar{x}\right)^{2}}{\sum\left(x_{i j}-\bar{x}\right)^{2}}}
\end{aligned}
$$

The online version of the original article can be found at http://dx.doi.org/10.1007/s00769-005-0055-y

Presented at AOAC Europe/Eurachem Symposium, March 2005,

Brussels, Belgium

E. Verdon $(\varangle) \cdot$ D. Hurtaud-Pessel $\cdot$ P. Sanders

AFSSA, Laboratoire d'Etudes et de Recherches sur les

Médicaments Vétérinaires et les Désinfectants,

BP 90230,35302 Fougères, France

e-mail: e.verdon@fougeres.afssa.fr 